\section{Low back pain: it is not always osteoarticular pathology}

\author{
Lumbalgia: ni siempre es patologia osteoarticular
}

A 84-year-old man, with excess weight and a previous history of hypertension, dyslipidemia, chronic obstructive pulmonary disease (COPD), osteoarticular disease and renal lithiasis, went to the emergency department with low back pain radiating to the front of the abdomen with a day of evolution, unresponsive to pain therapy. At admission, the patient was hypotensive and normocardial. Abdomen was distended, with bowel sounds diminished, little depressible, without palpable masses. Femoral pulses were little wide and symmetrical. During the evaluation the patient started precordial pain described as tightness, without irradiation, without relief or worsening factors, followed by syncope. Electrocardiogram in sinus rhythm, with ST segment depression in anterior leads. Analytically with anemia (not known), slight elevation of myocardial necrosis markers, d-dimers 4200ng / $\mathrm{mL}$. Urinalysis without changes. Computed tomography pulmonary angiography did not show signs of pulmonary thromboembolism. Upper abdominal and renalbladder ultrasonography revealed abdominal aortic aneurysm. Contrast-enhanced computed tomography scan of the abdomen and pelvis (Figure 1 and Figure 2) showed fusiform abdominal aortic aneurysm, with a maximum aneurysm diameter of $7.5 \mathrm{~cm}$, from the infrarenal abdominal aorta to the left common iliac artery, with signs of rupture (retrohemoperitoneum). The patient was submitted to emergent surgery with fatal outcome.

Low back pain is one of the symptoms that motivates more access to health care. ${ }^{1,2}$ It is estimated that $80 \%$ of the population, at any time, will present this symptomatology. ${ }^{1-3}$ There are multiple possible etiologies.2,3 Mostly they have multifactorial origin. ${ }^{3}$

The abdominal aortic aneurysms have a prevalence of 2-5\% in the general population, with a mortality rate of $80 \%$ in case of rupture. $1,4 \ln 91 \%$ of the cases it is accompanied by low back pain. ${ }^{1,4}$ It is crucial to include abdominal aortic aneurysm in the differential diagnosis of low back pain, ${ }^{1,4}$ especially in the presence of risk factors for developing it (male gender, age over 65, vascular risk factors, family history, chronic obstructive pulmonary disease, peripheral arteriopathy, among others), ${ }^{1,4}$ in order to diagnose early a pathology with high morbidity and mortality. The Point-of-care ultrasound, a widely used tool in emergency medicine, can contribute to this goal, since it detects the presence of abdominal aortic aneurysms in symptomatic individuals with high sensitivity and specificity. ${ }^{5}$ Therefore, the use of Point-of-care ultrasound in all patients admitted to the emergency room with abdominal pain or low back pain who present factors for the development of abdominal aortic aneurysms will be of added value.

\section{References}

1. Zúñiga Cedó E, Vico Besó L. Lumbalgia crónica y aneurisma de aorta abdominal. Semergen. 2013;39:e47e49

2. Reis e Silva MT. Lombalgia: um diagnóstico diferencial raro. Arquivos de Medicina. 2015;29:36-38.

3. Pérez Torres F, Pérez Caballero P, Núñez-Cornejo Palomares C, Ibáñez Juliá MJ, López Buades TL, Juliá Mollá C, et al. Lumbalgia. In: Belmonte MA, Castellano JA, Román JA, Rosa JC. Enfermedades reumatológicas SVR 2013. p741-768.

4. Hermida Pérez JA. Aneurisma de aorta abdominal infrarrenal, lumbalgia crónica, dislipidemia y enfermedad pulmonar obstructiva crónica. Med Gen Y Fam. 2016;5:59-63.

5. Kameda T, Taniguchi N. Overview of point-of-care abdominal ultrasound in emergency and critical care Journal of Intensive Care. 2016:4:53.
Figure 1. Contrast-enhanced computed tomography scan of the abdomen and pelvis (axial section): abdominal aortic aneurysm.

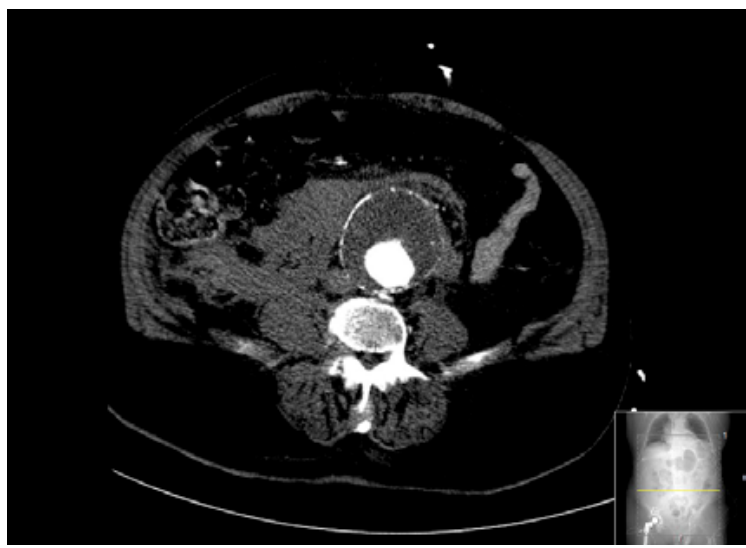

Figure 2. Contrast-enhanced computed tomography scan of the abdomen and pelvis (axial section): abdominal aortic aneurysm from the infrarenal abdominal aorta to the left common iliac artery.

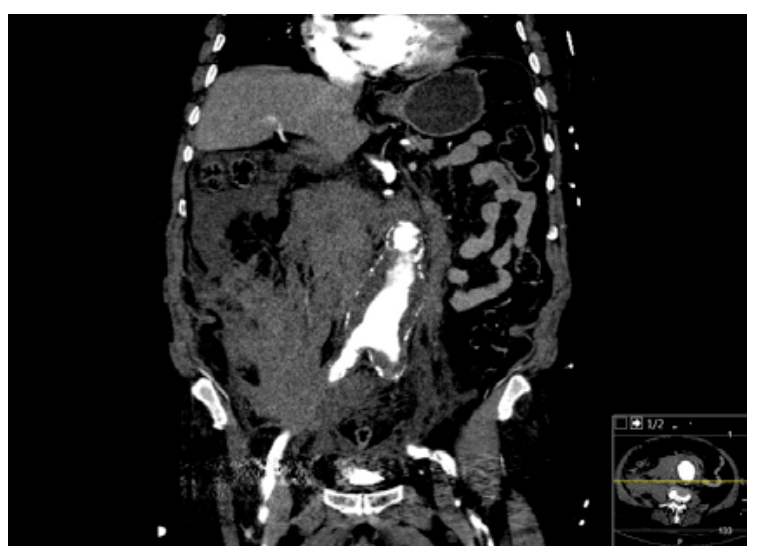

Diagnosis:

\section{Aneurysm from the infrarenal abdominal aorta with signs of rupture}

\section{Anabela Brito ${ }^{1}$, Irene Miranda ${ }^{2}$}

IInternal Medicine Department, Hospital Conde de Bertiandos, Unidade Local de Saúde do Alto Minho. Ponte de Lima, Portugal. 2 Internal Medicine Department, Hospital Santa Luzia, Unidade Local de Saúde do Alto Minho. Viana do Castelo, Portugal

Correspondencia: belanabrito@gmailcom

Cómo citar este artículo: Brito A, Miranda I

Low back pain: it is not always osteoarticular pathology. Galicia Clin 2019; 80 (2): 36

Recibido: 10/06/2018; Aceptado: 01/08/2018

http://doi.org/10.22546/52/1688 